\title{
Rare Acute Pancreatitis Cases Due to Different Antihypertensive Drugs: Four Cases
}

\author{
Gökhan Celbek ${ }^{1}$ Yusuf Aydın², Fatih Ermiş ${ }^{2}$,Adem Güngör ${ }^{3}$, Ali Kutlucan², Elif Önder \\ ${ }^{1}$ Department of Internal Medicine, Yenimahalle State Hospital, Ankara, Turkey \\ 2 Department of Internal Medicine, Duzce Unıversıty Faculty of Medicine, Duzce, Turkey \\ ${ }^{3}$ Department of Internal Medicine, Ataturk Unıversıty Faculty of Medicine, Erzurum, Turkey
}

\begin{abstract}
The most important reasons of acute pancreatitis (AP) are benign biliary tract diseases, metabolic diseases and alcoholism. Some drugs also (sulfonamides, thiazides, lysinopril, captopril, estrogens and tetracyclines) can induce AP. We herein report four cases of AP patients who were using different drugs. The first case was 73 years old male patient who has been using zofenopril for 4 weeks and the second patient was 24 years old female who was using furosemide after her pregnancy. Third one was using valsartan for one month. Fourth patient was using lysinopril for six weeks and resulted in AP. All patients had no known risk factors for pancreatitis. After cessation of the drugs, four patients recovered in a few days without any complications. AP due to zofenopril was firstly reported in our manuscript in the literature.
\end{abstract}

Keywords: Pancreatitis; antihypertensive agents; valsartan; zofenopril; furosemide

Received: 09.02.2014 Accepted: 02.03.2014

doi: 10.15824/actamedica.90033

\section{Introduction}

Acute Pancreatitis (AP) is an acute inflammatory disease of pancreas that can cause important morbidity and mortality with systemic inflammatory response syndrome (SIRS) in \%20 of patients (1). The most important reasons of AP are benign biliary tract diseases and alcoholism. The other etiological factors are post-ERCP (Endoscopic Retrograde Choleangiography), abdominal trauma, drugs, infections, hypercalcemia, postoperative, metabolic and idiopathic. Drugs strongly related with acute pancreatitis include sulfonamides, thiazides, lysinopril, captopril, estrogens and tetracyclines (2-3).

Although angiotensine converting enzyme (ACE) inhibitors are generally well tolerated drugs, a few AP cases had been reported which were related with usage of lisinopril, captopril, enalapril and ramipril (4). We are presenting four AP cases in this article, after excluding the other etiological factors. One of them is caused by zofenopril calcium, one of ACE inhibitors which was not reported before in literature, the other one by lisinopril and another is low dose of furosemide, a rare cause and the last one is caused by valsartan which is an angiotensin receptor blocker (ARB). They did not have a history of another drug or alcohol usage, smoking and any known drug allergy, either.

\section{Cases}

All the four cases had no history of fever, chills, melena, hematochesia, dysuria and change in character of stool or urine. Further there was not any history of biliary tract disease, recent abdominal trauma or surgery and viral infection in their medical history. They also did not have a history of another drug or alcohol usage, smoking and any known drug allergy, either. The laboratory test results of all the patients on admission and 48th hour are listed in table 1.

\section{Case 1}

73 years old male patient was admitted to hospital with a complaint of belt-like radiated abdominal pain that began 2 days ago. He had a history of hypertension for 2 years and a new medication, zofenopril calcium $30 \mathrm{mg} /$ day, was started 4 weeks ago. His blood pressure was $165 / 86 \mathrm{mmHg}$ and the other vital signs were in normal range. There was only epigastric tenderness with a mild abdominal distension and normal bowel sounds.

The abdominal ultrasonography (USG) showed normal gallbladder, no hepatobiliary ductal dilatation or pericholecystic fluid and no evidence of gallstones. So AP of this patient is thought to be related with zofenopril calcium usage and he was hospitalized. Zofenopril calcium was stopped and supportive medical treatment including intravenous fluids and analgesics were given. He recovered over 48 hours. Serum amylase and lipase levels were returned to normal (Table 1). Zofenopril calcium was changed 
with metaprolol treatment and patient was discharged from hospital.

\section{Case 2}

24 years old female patient was admitted to hospital with a complaint of abdominal pain that did not relieve with non-steroidal anti-inflammatory drugs. It was started from epigastric region one day ago and radiated to both upper quadrants of abdomen and to the back. She had not any symptoms other than nausea and vomiting. She was using furosemide 40 $\mathrm{mg} /$ day for 2 weeks. All the vital signs were in normal range. There was generalized abdominal pain but it was prominent in epigastric region.
The abdominal USG showed normal gallbladder, no hepatobiliary ductal dilatation or pericholecystic fluid and no evidence of gallstones. In double spiral-phase contrast-enhanced $\mathrm{CT}$ there was a minimal edematous appearance of pancreas. So, AP of this patient is thought to be related with furosemide usage and patient was hospitalized. Furosemide was stopped and supportive medical treatment including intravenous fluids and analgesics were given. Four days after furosemide cessation amylase and lipase levels were regressed to $100 \mathrm{IU} / \mathrm{L}$ and $45 \mathrm{IU} / \mathrm{L}$, respectively. Patient was discharged from hospital with recommendation of follow-up controls.

Table 1. The laboratory test results of case 1 , case 2 and case 3 on admission and 48th hour in hospital follow up.

\begin{tabular}{|c|c|c|c|c|c|c|c|c|c|}
\hline Variables & $\begin{array}{c}\text { Normal } \\
\text { values }\end{array}$ & $\begin{array}{c}\text { Case } 1 \\
\text { On } \\
\text { admissi } \\
\text { on }\end{array}$ & $\begin{array}{c}\text { Case } 1 \\
48^{\text {th }} \\
\text { hour }\end{array}$ & $\begin{array}{l}\text { Case } 2 \\
\text { On } \\
\text { admiss } \\
\text { ion }\end{array}$ & $\begin{array}{c}\text { Case } 2 \\
48^{\text {th }} \\
\text { hour }\end{array}$ & $\begin{array}{l}\text { Case } 3 \\
\text { On } \\
\text { admiss } \\
\text { ion }\end{array}$ & $\begin{array}{c}\text { Case } 3 \\
48^{\text {th }} \\
\text { hour }\end{array}$ & $\begin{array}{l}\text { Case } 4 \\
\text { On } \\
\text { admiss } \\
\text { ion }\end{array}$ & $\begin{array}{c}\text { Case } 4 \\
48^{\text {th }} \\
\text { hour }\end{array}$ \\
\hline $\begin{array}{c}\text { Amylase } \\
\text { (IU/L) }\end{array}$ & 25回125 & 612 & 93 & 1054 & 100 & 2382 & 193 & 2528 & 1193 \\
\hline Lipase (IU/L) & 8?78 & 753 & 126 & 1039 & 45 & 6000 & 83 & 1389 & 657 \\
\hline LDH (IU/L) & 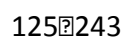 & 350 & 202 & 382 & 192 & 332 & 220 & 193 & 297 \\
\hline $\begin{array}{l}\text { Hemotocrit } \\
\text { (Htc) (\%) }\end{array}$ & \%37?52 & 43 & 40 & 39,9 & 36.8 & 34.6 & 31 & 43,3 & 38 \\
\hline $\begin{array}{c}\text { White blood } \\
\text { cell (WBC) } \\
\text { (/mm3) }\end{array}$ & $\begin{array}{c}\text { 5200?12 } \\
400\end{array}$ & 12300 & 9850 & 8800 & 8730 & 8940 & 3810 & 25,1 & 14,9 \\
\hline $\begin{array}{l}\text { Glucose } \\
\text { (mg/dl) }\end{array}$ & 70?115 & 168 & 112 & 126 & 98 & 139 & 103 & 107 & 103 \\
\hline $\begin{array}{l}\text { Calcium } \\
\text { (mg/dl) }\end{array}$ & 8.4回10,2 & 8.9 & 9.3 & 9,6 & 8.9 & 9.7 & 8.6 & 9 & 7,7 \\
\hline $\begin{array}{c}\text { Triglyceride } \\
\text { (mg/dl) }\end{array}$ & 40?150 & 128 & 86 & 203 & 182 & 158 & 140 & 103 & 125 \\
\hline $\begin{array}{c}\text { Aspartate } \\
\text { aminotransfer } \\
\text { ase AST IU/L }\end{array}$ & 5回34 & 22 & 11 & 19 & 10 & 144 & 16 & 17 & 25 \\
\hline $\begin{array}{c}\text { Gama } \\
\text { glutamyl } \\
\text { transferase) } \\
\text { GGT IU/L }\end{array}$ & 9??36 & 51 & 49 & 17 & 13 & 90 & 69 & 10 & 35 \\
\hline $\begin{array}{c}\text { Alanine } \\
\text { aminotransfer } \\
\text { ase (ALT) } \\
\text { (IU/L) }\end{array}$ & 0]55 & 32 & 14 & 130 & 10 & 61 & 32 & 18 & 32 \\
\hline
\end{tabular}




\section{Case 3}

45 years old female patient admitted to hospital with the complaint of abdominal pain which was located in epigastric region and radiated to all abdomen and back. In her medical history there was only hypertension. She was using amlodipine $10 \mathrm{mg} \mathrm{qd}$, but treatment was changed to combination of valsartan $160 \mathrm{mg}$ qd and amlodipine $5 \mathrm{mg}$ qd one month ago. Her blood pressure was $149 / 80 \mathrm{mmHg}$ and the other vital signs were in normal range. In her abdominal physical examination there was only generalized abdominal pain.

In double spiral-phase contrast-enhanced CT there was a minimal edematous appearance of pancreas, gall bladder was in normal appearance and it did not have any stone or mass. So AP of this patient is thought to be related with valsartan usage and patient was hospitalized. Valsartan treatment was stopped and parenteral fluid and supportive treatments were given. After 5 days, her laboratory values were returned to normal and clinical improvement was seen and she was discharged from hospital with the treatments of amlodipine $10 \mathrm{mg} q d$ and metoprolol $50 \mathrm{mg}$ qd.

\section{Case 4}

38 years old female patient admitted to hospital with nausea, vomiting and abdominal pain that was started in periumblical area and radiated to the entire abdomen. She only had a history of hypertension for one year and lisinopril $10 \mathrm{mg} /$ day treatment was started 6 weeks ago. Her blood pressure was 150/85 $\mathrm{mmHg}$ and the other vitals were in normal range. In abdominal physical examination there was only a tenderness in the epigastric region. Because of the increased amylase and lipase (2528 and 1389, respectively), patient was hospitalized with the diagnosis of acute pancreatitis. Hepatobiliary USG was consistent with normal gallbladder, no hepatobiliary ductal dilatation or pericholecystic fluid and no evidence of gallstones. In abdominal CT increased size of the pancreas was seen. Decreased density of parenchyma in the body and the tail part of the pancreas and markedly increase in density of the surrounding retroperitoneal fat tissue (inflammation) and free fluid collection were also detected. So AP of this patient was thought to be related with lisinopril usage after exclusion of other etiologic factors. Lisinopril treatment was stopped and supportive medical treatments were given. She was recovered over 48 hours. Serum amylase and lipase levels were returned to normal after discontinuing of lisinopril treatment. Lisinopril was changed with amlodipin 10 $\mathrm{mg}$ qd treatment and patient was discharged from hospital.

\section{Discussion}

Acute pancreatitis can present in a spectrum of mild disease to multisystem organ failure and death. There are many causes; gallstones and alcohol abuse accounting for $80 \%$ of all cases in the United States and Western Europe. The remaining $20 \%$ of cases are due to various other causes $(5,6)$. Mostly known causes are hyperlipidemia, diabetes mellitus, uremia, hyperparathyroidism, idiopathic, ampullar region diseases, infections, pregnancy, some toxins etc. Also some drugs can induce pancreatitis. Mostly known are immunosupressives, sulfonamides, metronidazole, tetracycline, corticosteroids, 5-ASA, estrogens, some ACE inhibitors, isoniazid, rifampin. Lankisch et al. reported that drug induced pancreatitis percentage was 1.4 (7). Although drug induced AP are rare, there are reports of AP cases with ACE inhibitors especially with captopril, lisinopril, enalapril $(2,8,9)$, ramipril (4) and perindopril (10). The pathophysiology of ACE inhibitor-induced pancreatitis remains speculative but it has been proposed by some authors to be due to localized angioedema of pancreatic tissue with ensuing ductal obstruction (11-13). ACE inhibitors have been associated with upper airway angioedema possibly due to altered bradykinin metabolism; this may also be the mechanism for pancreatic angioedema (14). ACE inhibitors can also induce hypoglycemia, suggesting a directly toxic effect on pancreatic tissue (12). Although some researchers have proposed the formation of auto-antibodies by ACE inhibitors to pancreatic acinar cells (6). The exact mechanism by which they may cause acute pancreatitis remains still to be unknown. In conclusion, although there was reported AP cases related with lisinopril usage, but, to our knowledge, this is the first report in the literature of zofenopril calcium induced pancreatitis. As a result, clinicians need to be aware of the distinct possibility of AP when evaluating a patient taking zofenopril calcium who presents with abdominal pain.

Furosemide is a commonly used diuretic which inhibits sodium reabsorption in the ascending limb of the loop of henle and probably in other segments of the tubule (15). Jones et al. reported furosemide induced AP. Buchanan et al. also reported a chain of 3 cases of furosemide induced AP. These 3 patients had some different co-morbidities such as black race, chronic alcohol intake, heart failure and DM history. These patients also had used high doses of furosemide. AP 
was found to be developed after 8-18 hour of high doses of furosemide (16), but our patient had no known possible risk factors of AP (DM, alcohol or heart failure), and she was very young and used low dose of furosemide. In our patient AP symptoms were developed after 14th day of furosemide. The mode of furosemide action on the pancreas is unknown, cellular derangement by hypokalemia, impaired blood flow, inspisated secretions in the ducts, or allergic mechanisms are all possible. Nevertheless, that furosemide is capable of producing this potentially dangerous complication to all who use it is a matter of vital importance (15). The case we presented showed us that clinicians should not forget, in patients who are young who have no co-morbid situations and using low dose furosemide or when there is a necessity of furosemide usage there is a risk of AP development. So they should not disregard questioning of furosemide usage in patients with abdominal pain.

ARB? ? are thought to be important in regulation of pancreatic secretion and microcirculation, but the mechanism of pancreatitis induced by angiotensin II receptor antagonists remains unclear (17). Pancreas contains a local renin-angiotensin system (RAS), which is subject to activation by experimental pancreatitis. In the exocrine pancreas, angiotensin II receptor subtypes AT1 and AT2 have been localized in the pancreatic ducts, blood vessels and acinar cells. We hypothesize that local RAS activities may have a potential role in regulating pancreatic acinar digestive enzyme secretion (18). In literature as the cause of AP, there was not any cases of angiotension receptor blocker reported other than losartan $(19,20)$, irbesartan $(17,21)$ and telmisartan (22) usage. In literature, our case is the first reported AP case resulted from valsartan usage. As a result, ARB drugs, which are commonly used in the treatment of hypertension should be kept in mind as a cause of AP.

\section{Conclusion}

Zofenopril, valsartan and high dose furosemide are frequently used drugs in hypertension, heart failure and renal diseases. In this context clinicians have to keep in mind that these drugs have potential risk for AP. Especially patients who have co-morbid diseases like heart failure, hypertension, alcohol intake, are under the risk of AP. We also herein report first case of zofenopril, valsartan and low dose furosemide induced AP.

\section{References}

1. Tonsi A.F, Bacchion M, Crippa S, Malleo G, Bassi C Acute pancreatitis at the beginning of the 21st century: The state of the art. World J Gastroenterol 2009;15:2945-2959.

2. Hazinedaroğlu S, Kayaoğlu H.A, Karayalçın K Do improvements in diagnostic and therapeutic modalities affect the prognosis of acute pancreatitis?. Turkiye Klinikleri J Med Sci 2005;25:383-386.

3. Gershon T, Olshaker JS Acute pancreat itis fo llowing lisinopril rechallenge. Am J Emerg Med 1998;16:523-524.

4. Kanbay M, Korkmaz M, Yılmaz U, Gur G, Boyacıoglu S Acute pancreatitis due to ramipril therapy. Postgrad Med J 2004;80:617-618.

5. Steinberg W, Tenner S Acute pancreatitis. N Engl J Med 1994;330:1198-1210.

6. Dimagno EP. Pancreatitis, chap 86, In Kelley WN, DeVita VT, DuPont HL (Eds): Textbook of Internal Medicine. New York, NY, JB Lippincott, 1992.p.531-534.

7. Lankisch PG, Dröge $M$, Gottesleben $F$ Drug induced acute pancreatitis: incidence and severity. Gut.1995;37:565-567

8. Standridge JB Fulminant pancreatitis associated with lisinopril therapy. South Med J 1994;87:179-181.

9. Maliekal J, Drake CF Acute pancreatitis associated with the use of lysinopril. Ann Pharmacother 1993;278:1465]1466.
10. Gallego-Rojo F.J, Gonzalez-Calvin JL, Guilarte J, CasadoCaballero F.J, And Bellot V Perindopril-Induced Acute Pancreatitis. Digestive Diseases and Sciences 1997;42:1789-1791.

11. Dabaghi S ACE inhibitors and pancreatitis. Ann Intem Med. 1991;115:330-331.

12. Roush MK, McNutt RA, Gray TF The adverse effect dilemma: Quest for accessible information. Ann Intem Med. 1991;114:298-299.

13. Tilkemeier $P$, Thompson PD Acute pancreatitis possibly related to enalapril (Letter). N Engl J Med 1988;318:12751276

14. Williams $\mathrm{GH}$ Converting enzyme inhibitors in the treatment of hypertension. N Engl J Med 1988;319:15171525

15. Jones $\mathrm{PE}$, Oelbaum $\mathrm{MH}$ Frusemide-induced pancreatitis. Br Med J. 1975;1:133-134.

16. Buchanan N, Cane RD Frusemid-induced pancreatitis. Br Med J. 1977;2:1417.

17. Fisher AA, Bassett ML Acute pancreatitis associated with angiotensin II receptor antagonists. Ann Pharmacother. 2002;36:1883-1886.

18. Tsang SW, Cheng $\mathrm{CH}$, Leung PS The role of the pancreatic renin-angiotensin system in acinar digestive 
enzyme secretion and in acute pancreatitis. Regul Pept. 2004;119:213-219.

19. Birck R, Keim V, Fiedler F, van der Woude FJ, Rohmeiss P Pancreatitis after losartan. Lancet. 1998;351:1178

20. Bosch $X$ Losartan-induced acute pancreatitis. Ann Intern Med.1997;127:1043-1044.
21. Famularo G, Minisola G, Nicotra GC, De Simone C Acute pancreatitis associated with irbesartan therapy. Pancreas. 2005;31:294-295.

22. Baffoni L, Durante V, Grossi M Acute pancreatitis induced by telmisartan overdose. Ann Pharmacother. 2004;38:1088. 